\title{
¿Alternativas para la gestión del agua y el desarrollo regional? Confllicto por la presa El Zapotillo*
}

\section{Heliodoro Ochoa García}

\begin{abstract}
La presa El Zapotillo se vende en el discurso oficial como un proyecto de desarrollo para abastecer de agua a las ciudades de León y Guadalajara. Sin embargo, el costo social de este proyecto es asumido de manera injusta por la región de los Altos de Jalisco, comprometiendo con ello su propio desarrollo. En este artículo se analiza el conflicto en torno a esta empresa desde una perspectiva regional, tomando en cuenta las alternativas sociales.
\end{abstract}

\section{ESCENARIO DE}

\section{CONFLICTOS ENTRELAZADOS}

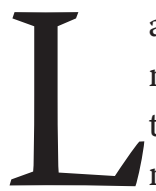

a presa, o mejor dicho, el sistema El Zapotillo nace de dos proyectos fallidos y uno incompleto que llevaron a su imposición por el gobierno: la presa San Nicolás, la presa Arcediano y el sistema El Salto-La Zurda-Calderón. Es apreciada como la pieza hidráulica central que permitiría aprovechar los caudales de la cuenca del río Verde para materializar los proyectos hidráulicos más grandes destinados al abastecimiento público urbano en el occidente de México. Las justificaciones de los promoventes son garantizar el abastecimiento de agua en las ciudades de Guadalajara y León, proteger el lago de Chapala y detener el abatimiento de acuíferos aledaños a estas dos urbes. Sin embargo, el manejo de información es impreciso y se presta a confusiones. Por ejemplo, no existe proyecto para alimentar los acuíferos o para proteger áreas de recarga, los proyectos de abastecimiento y grupos a beneficiar dentro de las ciudades no se han dado a conocer a detalle y no se cuantifican los supuestos ahorros en el agua extraída del lago de Chapala.

Lo peor del caso es que no se plantean proyectos para los Altos de Jalisco que permitan recuperar el equilibrio de aguas subterráneas o, bien, gestionar la escasez 
de aguas superficiales que día con día amenaza la vida y la producción en esta región semidesértica, la más vulnerable de Jalisco ante escenarios de cambio climático. ${ }^{1}$ Los estudios oficiales de disponibilidad de agua en esta región muestran la sobreexplotación y el ritmo acelerado de abatimiento en años recientes. A partir de los datos se concluye que el agua disponible es menor a la demanda, lo cual hace urgente la necesidad de ordenar los usos y los aprovechamientos que ya existen en la región antes de aumentar la presión sobre el recurso o de pensar en realizar un transvase. ${ }^{2}$ No obstante, los estudios justificativos del proyecto «El Zapotillo y el análisis de otras alternativas» se hicieron en favor de Guanajuato, mientras que los impactos en Los Altos de Jalisco aparecen como pasivos. Todavía en 2013, la región no tiene concesión de aguas, mucho menos proyectos o dinero asignado para ningún tipo de obras de aprovechamiento del sistema El Zapotillo. Queda en evidencia que la prioridad son las ciudades y el uso público urbano, dejando en riesgo el tejido productivo rural y las pequeñas poblaciones dispersas por toda la región de los Altos de Jalisco, que en años recurrentes con poca lluvia sufre severos estragos poniendo en dificultades la economía y vida cotidiana de más de 800 mil habitantes.

Una ciudad como la Zona Metropolitana de Guadalajara (ZMG) funciona con un modelo de gestión que genera conflictos socioambientales. Entre los más evidentes, están los directa e indirectamente relacionados con el agua. Los costos ambientales de la contaminación y el agotamiento de fuentes de agua se agregan a la irresponsabilidad, negligencia, ineficiencia y corrupción de organismos operadores - como el Sistema Intermunicipal para los Servicios de Agua y Alcantarillado (SIAPA) - y usuarios del recurso. El costo ambiental de estas fallas ya se traslada a los sistemas hidrológicos, poblaciones periurbanas y rurales hasta un radio de 90 $\mathrm{km}$ más allá de la ciudad capital. ${ }^{3}$ La metrópoli debería asumir la deuda ambiental hidrológica que tiene desde hace sesenta años con las comunidades de la ribera del río Santiago, el lago de Chapala y la periferia, de donde ha obtenido su agua desde entonces y a donde expulsa sus residuos, lastimando la salud ambiental del entorno y encareciendo el recurso indispensable para la vida.

Este modelo de metabolismo urbano es calificado como depredador, ${ }^{4}$ injusto y causante de enfermedad y muerte en las poblaciones que asumen el costo ambiental, las cuales organizadas en movimientos sociales llevan más de 15 años alzando la voz para reclamar justicia y defender el territorio donde habitan: El Salto-Juanacatlán, pueblos de la Barranca del río Santiago, comunidades del lago de Chapala, poblaciones de la periferia sur y oriente de la ciudad y, más recientemente, las comunidades de Temacapulín, Acasico y Palmarejo.

La zMG no ha fijado sus límites de crecimiento y consumo. La compensación o responsabilidad por deuda y suma de daños ambientales tampoco tiene efecto ni castigo para instituciones, gobernantes, empresarios o ciudadanos que se corrompen, violan la ley y omiten recomendaciones internacionales. El saldo: aumento de conflictos y constitución de movimientos socioambientales que se expanden para defender el agua (entre otros bienes y recursos) y reclamar un medio ambiente sano. Los costos ambientales por degradación ambiental o agotamiento de recursos se reconocen a la alza, ${ }^{5}$ mientras se conforma un reclamo social cada vez más articulado de lo local a lo global, que exige alternativas, proyectos, políticas ambientales $-\mathrm{y}$ del agua- que sean más justas y equitativas. ${ }^{6}$

Los pueblos directamente afectados por la inundación que puede causar el embalse de la presa El Zapotillo conformaron en 2005 el Comité Salvemos Temaca, Acasico y Palmarejo. Desde entonces, son innumerables las acciones legales y de protesta, difusión y exigencias que han realizado en una gran variedad de espacios locales e internacionales donde convocan la participación de la sociedad, gobiernos, instituciones, académicos, jueces, organizaciones y movimientos sociales, fundaciones, medios de comunicación, para dar a conocer la lucha por el agua y la defensa de sus derechos. Uno de sus grandes logros es que «los ojos del mundo están puestos en Temaca», tal como lo expresa una de sus frases.

El descontento social indica que la gestión del proyecto no ha sido adecuada en ninguna de sus etapas. Ahora que la cortina de la presa lleva un avance en construcción de 65\%, los pueblos afectados, junto con un sector de la sociedad y la academia, insisten en la búsqueda de alternativas antes que el agua comience a inundar las poblaciones. A este reclamo se une la asociación civil alteña Conredes - con sede en San Juan de los Lagos-, que insiste en el rediseño del sistema El Zapotillo y en la cancelación del acueducto a León, bajo el argumento de que los estudios justificativos son de hace 20 años; ahora no hay agua de sobra para un transvase porque la población y la producción agropecuaria de la región creció sustancialmente desde entonces. Eso no está considerado ni evaluado en los estudios justificativos del proyecto 
de presa ni en el transvase a la cuenca del río Lerma, donde se asienta la ciudad de León.

\section{EN BUSCA DE ALTERNATIVAS SOCIALES}

La alternativa social puede ser entendida como un conjunto de «acciones y procesos impulsados por una pluralidad de colectivos ciudadanos, movimientos sociales o grupos étnicos que promueven posibles modos de vida y formas diversas de organización, diferentes a las impuestas por el sistema dominante». ${ }^{7}$ De acuerdo con Luengo, algunas alternativas sociales se distinguen por ser acciones comunitarias y aplicaciones tecnológicas para incrementar la calidad de vida. Se asocian con movimientos sociales autónomos encaminados a resolver problemas o a impulsar iniciativas que favorezcan a la colectividad, buscando la transformación de las instituciones públicas o comunitarias, en este caso para una gestión integral sustentable del agua. ${ }^{8}$ Sin embargo, el proyecto que proponen las instancias oficiales es en beneficio prioritario para Guadalajara y León, lo cual significa una amenaza y riesgo para los afectados directos e indirectos en la región de los Altos.

Ante un escenario de conflictividad y demanda urbana de agua, la presa El Zapotillo es apreciada por las autoridades como una infraestructura estratégica para articular un sistema de presas interconectado que conforme a decretos, acuerdos y convenios de distribución y usos - permita aprovechar las aguas reservadas de la cuenca del río Verde en beneficio de Jalisco (Guadalajara) y Guanajuato (León) para uso público urbano: 372,139 millones de metros cúbicos (Mm3) anuales para aquél y 119,837 Mm3 anuales para éste. La región de Los Altos de Jalisco apenas consiguió quedarse con 12,600 Mm3 anuales como reserva para uso pecuario y también puede tomar 56,7648 Mm3 anuales para uso público urbano como parte de la reserva de Jalisco. ${ }^{9}$

Aprovechar las aguas del río Verde, dice el acuerdo firmado en 2005, pretende «colaborar con el rescate de la cuenca Lerma-Chapala». Entonces, ¿cuál es el beneficio para la región de los Altos si sus acuíferos se están agotando, las sequías son más prolongadas y las poblaciones no tienen agua y se pone en riesgo a las unidades de producción rural? Reducir la disponibilidad de agua en la región, imponer vedas, realizar el transvase y concesionar la distribución de agua a una empresa privada sin antes diseñar una política de ges- tión integral sustentable del agua no parece una buena alternativa para los alteños.

Las llamadas mesas de trabajo que los afectados por la presa han sostenido con autoridades del gobierno de Jalisco, en 2010 y 2013, apuntan a que las alternativas deben rehacer los convenios de distribución de agua entre los estados para que la totalidad de las aguas del río Verde sean para Jalisco y que la cortina de la presa sea a 60 metros para beneficiar a Guadalajara y a los Altos (no a Guanajuato), además de construir presas de menor tamaño sobre los afluentes del río Verde, especialmente en el cauce del río San Juan. Todo esto con el propósito fundamental de defender la soberanía del estado de Jalisco.

Las poblaciones alteñas tienen derecho - por decreto- de aprovechar parte de los volúmenes a almacenar en las presas El Zapotillo y El Salto (hasta $1.8 \mathrm{~m} 3 /$ seg), pero no se han dado a conocer estudios o proyectos al respecto, según lo establecido en la cláusula tercera del acuerdo firmado por la Conagua, Jalisco y Guanajuato en 2005. Asimismo, los municipios alteños que opten por esta fuente de abastecimiento deben asumir el pago de la infraestructura hidráulica necesaria y pagar a la empresa operadora del sistema de acueducto (y sus ramales) el precio que establezca por concepto de los volúmenes de agua utilizados para su distribución, pues se trata de una concesión privada de agua para los próximos treinta años. Los ayuntamientos que autoricen la subdivisión y cambio de uso de suelo para favorecer la construcción del acueducto deberán asumir las consecuencias si no están atentos a defender sus intereses y necesidades sociales.

Por otro lado, el gobierno de Jalisco promete que el volumen reservado para uso pecuario será aprovechado mediante 3500 bordos tipo abrevadero; ${ }^{10}$ sin embargo, ello implica la revisión de disponibilidad de aguas en la cuenca y probablemente la regularización de aprovechamientos que ya existen sin tener un registro. De esta manera, la promesa del gobierno de Jalisco debe acordarse formalmente involucrando a la Comisión Nacional del Agua (Conagua) y sus órganos auxiliares - Consejo de Cuenca del Río Santiago y Comisión de Cuencas Altos de Jalisco- como instancias de coordinación y concertación, apoyo, consulta y asesoría, según lo establece la Ley de Aguas Nacionales.

Pero, ¿cómo se decidirá a quién dotar de abrevaderos y a quién no? Los representantes de los distintos usuarios - particularmente el pecuario - se verán obligados a mediar el conflicto que representa administrar 
la escasez de agua y distribuir los recursos de esta oferta que el gobierno de Jalisco lanza como alternativa a los ganaderos. Al mismo tiempo, todos los usuarios de agua están sujetos a los operativos de inspección, sanciones y multas que la Conagua implementa desde hace un par de años para garantizar que las aguas lleguen a El Zapotillo. Gracias a esto, la tensión social y política aumenta aunado a la presión por liberar los terrenos donde pasaría el acueducto. Los foros y reuniones realizados a lo largo de los últimos ocho años entre afectados, usuarios y autoridades, con la presencia de Conagua y la Comisión Estatal del Agua de Jalisco (CEA), no han solucionado el conflicto y no ofrecen respuesta a las demandas y compromisos adquiridos en múltiples mesas. Mientras tanto, la presa se continúa construyendo a un ritmo de dos mil metros cúbicos de concreto al día y las comunidades siguen en la incertidumbre.

Ante un escenario futuro que anuncia menos agua disponible, de menor calidad y una mayor demanda, es muy probable que el acceso y la transacción de agua entre regiones no será gratuita ni pacífica. La vida de pueblos y ciudades alteñas tienen una alta vulnerabilidad por falta de agua y su capacidad de resiliencia ambiental e institucional es muy limitada, ocasionando una latente disputa entre el campo y la ciudad por el acceso al agua de la cuenca del río Verde. La transmisión del costo directo de inundación es para Temacapulín, Acasico y Palmarejo, mientras los costos de sequía y baja disponibilidad de agua se reparten a toda la región alteña. Surgen las preguntas, ¿qué acciones emprenderán los ganaderos, empresarios, presidentes municipales y sociedad en general de los Altos para defender el agua que ya necesitan?, ¿se opondrán abiertamente al acueducto y transvase de agua a León?, ¿se logrará rediseñar el proyecto de presa para no inundar ni exponer a riesgo alguno a Temacapulín, Acasico y Palmarejo?, ¿lograrán los Altos de Jalisco figurar con claridad y ser tomados en cuenta en la agenda de gestión del agua de su propia región? 
* El presente texto forma parte de los resultados de la investigación «Agua para el desarrollo regional en los Altos de Jalisco», proyecto financiado por la Asociación Ganadera Local de San Juan de los Lagos, Jalisco (mayo-octubre 2013).

1 Mauricio Alcocer Ruthling (coordinador) (2013), «Plan Estatal de Acción ante el Cambio Climático del Estado de Jalisco», ponencia presentada en la Universidad Autónoma de Guadalajara, 22 de marzo de 2013.

2 Registro Público de Derechos de Agua (REPDA), 〈http://www. conagua.gob.mx/Repda.aspx?n1=5\&n2=37\&n3=115».

3 Mario E. López-Ramírez y Heliodoro Ochoa-García (2012), «Geopolítica del agua en la Zona Metropolitana de Guadalajara: historia y situación actual del espacio vital», en Heliodoro Ochoa-García y Hans-Joachim Bürkner (coordinadores), Gobernanza y gestión del agua en el occidente de México, la metrópoli de Guadalajara (Colección Alternativas al Desarrollo), Tlaquepaque, ITEso.

4 Joan Martínez Alier (2011), El ecologismo de los pobres: conflictos ambientales y lenguajes de valoración, Barcelona, Icaria.

5 Cfr. inegi (2011), Sistema de Cuentas Nacionales de Méxi- co, Cuentas económicas y ecológicas de México 2005-2009, Aguascalientes, INEGI.

6 Darcy Tetreault, Heliodoro Ochoa-García y Eduardo Hernández-González (coordinadores), (2012) Conflictos socioambientales y alternativas de la sociedad civil, Tlaquepaque, ITESO.

7 Enrique Luengo González (2013), «Las alternativas emergentes: procesos y acciones para una nueva reorganización social», inédito, Guadalajara, CIFS-ITESO, p. 7.

8 Luengo González (2013), op. cit.

9 Decreto que reforma la reserva de las aguas nacionales superficiales en la cuenca del río Verde, para usos doméstico y público urbano, Diario Oficial de la Federación (17 de noviembre de 1997) y Acuerdo de coordinación para los usos y distribución de las aguas superficiales de la cuenca del río Verde firmado por la Conagua y los gobiernos de Jalisco y Guanajuato en septiembre de 2005.

10 Analy S. Nuño (2013), «Acuerdan gobierno estatal y la Conagua extracción de agua en zona de Los Altos», La Jornada Jalisco, 16 de agosto.

\section{Referencias}

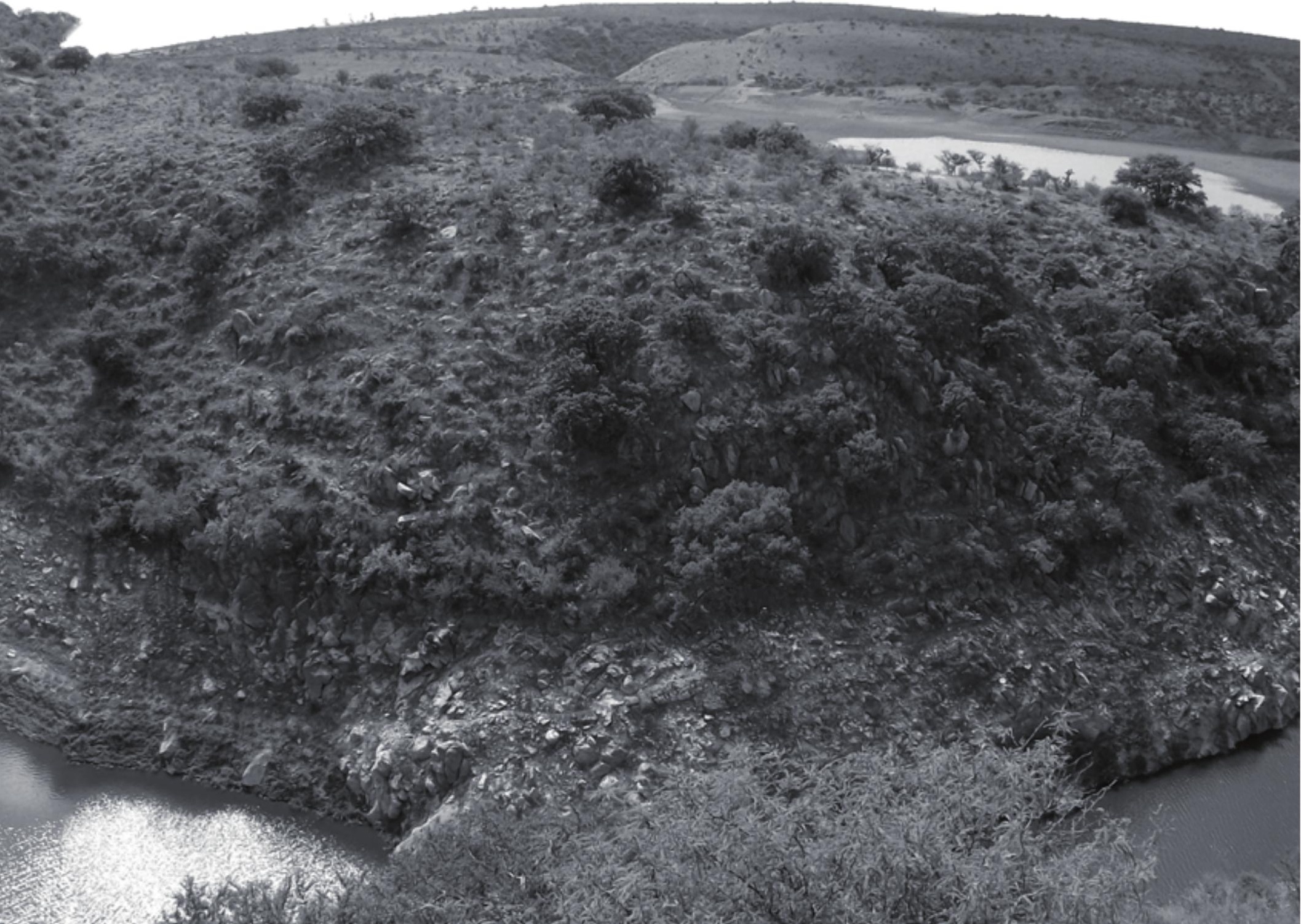

